research

\title{
Early leptin blockade predisposes fat-fed rats to overweight and modifies hypothalamic microRNAs
}

\author{
Charlotte Benoit ${ }^{1,2}$, Hassina Ould-Hamouda, ${ }^{1,2}$, Delphine Crepin ${ }^{1,2}$, Arieh Gertler ${ }^{3}$, \\ Laurence Amar ${ }^{1,2}$ and Mohammed Taouis ${ }^{1,2}$ \\ ${ }^{1}$ Neuroendocrinologie Moléculaire de la Prise Alimentaire, University of Paris-Sud, UMR 8195, Orsay F-91405, France \\ ${ }^{2}$ Neuroendocrinologie Moléculaire de la Prise Alimentaire, CNRS, Centre de Neurosciences Paris-Sud, UMR 8195, \\ Orsay F-91405, France \\ ${ }^{3}$ Faculty of Agricultural, Food and Environmental Quality Sciences, The Institute of Biochemistry, Food Science, and \\ Nutrition, The Hebrew University of Jerusalem, PO Box 12, 76100 Rehovot, Israel
}

Correspondence should be addressed to M Taouis

Email

mohammed.taouis@u-psud.fr

\begin{abstract}
Perinatal leptin impairment has long-term consequences on energy homeostasis leading to body weight gain. The underlying mechanisms are still not clearly established. We aimed to analyze the long-term effects of early leptin blockade. In this study, newborn rats received daily injection of a pegylated rat leptin antagonist ( $p R L A)$ or saline from day $2(d 2)$ to d13 and then body weight gain, insulin/leptin sensitivity, and expression profile of microRNAs (miRNAs) at the hypothalamic level were determined at d28, d90, or d153 (following 1 month of high-fat diet (HFD) challenge). We show that pRLA treatment predisposes rats to overweight and promotes leptin/insulin resistance in both hypothalamus and liver at adulthood. pRLA treatment also modifies the hypothalamic miRNA expression profile at d28 leading to the upregulation of 34 miRNAs and the downregulation of four miRNAs. For quantitative RT-PCR confirmation, we show the upregulation of rno-miR-10a at $d 28$ and rno-miR-200a, rno-miR-409-5p, and rno-miR-125a-3p following HFD challenge. Finally, pRLA treatment modifies the expression of genes involved in energy homeostasis control such as UCPs and AdipoRs. In pRLA rat muscle, Ucp2/3 and Adipor1/r2 are upregulated at d90. In liver, pRLA treatment upregulates Adipor1/r2 following HFD challenge. These genes are known to be involved in insulin resistance and type 2 diabetes. In conclusion, we demonstrate that the impairment of leptin action in early life promotes insulin/leptin resistance and modifies the hypothalamic miRNA expression pattern in adulthood, and finally, this study highlights the potential link between hypothalamic miRNA expression pattern and insulin/leptin responsiveness.
\end{abstract}
Key Words
- postnatal leptin
- overweight
- leptin resistance
- insulin resistance
- microRNA
- high-fat diet

Journal of Endocrinology (2013) 218, 35-47

\section{Introduction}

Leptin acts at the hypothalamic level to inhibit food intake and to increase energy expenditure (Ahima \& Flier 2000). Through its long isoform receptor OBRb, leptin stimulates anorexigenic and inhibits orexigenic neurons of the arcuate nucleus (ARC) that project to the paraventricular nucleus (PVN) to adjust energy homeostasis (Schwartz et al. 2000).

In the early postnatal period, leptin plays an independent role from regulating body weight and fat size. In newborn rodents, a peak of leptin appears during the http://joe.endocrinology-journals.org DOI: 10.1530/JOE-12-0561
(C) 2013 Society for Endocrinology Printed in Great Britain 
second week of life, which is not related to the regulation of food intake (Ahima et al. 1998, Mistry et al. 1999, Proulx et al. 2002). This peak has been related to a maternal origin through lactation (Stocker et al. 2004, Bautista et al. 2009). Other studies mentioned an endogen origin based on positive correlations between leptin plasma levels and leptin adipose tissue mRNA expression during the second week of life (Kirk et al. 2009). Furthermore, in newborn rats, leptin plasma levels were correlated with leptin mRNA expression in both cortex and pituitary gland (Morash et al. 2001). At this stage, leptin also regulates the expression of hypothalamic neuropeptides (Proulx et al. 2002) and contributes to the hypothalamic neural network maturation through the outgrowth of neuronal projections from the ARC to paraventricular, dorsomedial, and lateral hypothalamic nuclei that begins from day 6 after birth in rodents (d6) and ends at the second postnatal week (Bouret et al. 2004a,b, Valerio 2006, O'Malley et al. 2007). In leptin-deficient $o b / o b$ mice, hypothalamic projections are disturbed and partially restored following postnatal leptin treatment (Bouret et al. 2004a,b). In addition, newborn rats treated with leptin exhibit hyperleptinemia, hyperinsulinemia associated with a higher body weight gain, and hypothalamic leptin resistance at the adulthood (Toste et al. 2006, Vickers et al. 2008, Kirk et al. 2009). We have recently shown that blocking leptin action using a leptin antagonist predisposed newborn rats to body weight gain and leptin resistance at adulthood (Attig et al. 2008). Consequently, all events that affect leptin action during this developmental period such as inappropriate diet of dams during pregnancy (high caloric diet or energy restriction) impair hypothalamic neuronal projections and promote later in life metabolic and endocrine disorders (Kirk et al. 2009, Patel et al. 2009).

This clearly indicates that the alteration of leptin levels in early life similarly affects energy homeostasis and insulin/leptin responsiveness through most likely different mechanisms but with identical consequences. These mechanisms are not yet elucidated; thus, we hypothesized that high leptin levels impair leptin signaling and this could be mimicked by leptin antagonist. Therefore, leptin antagonist may constitute an important pharmacological tool to further investigate the underlying mechanisms of leptin action at this stage.

As leptin is crucial for hypothalamic neural organization in early life, we hypothesize that postnatal leptin may induce and initiate deep changes at the transcriptional and posttranscriptional levels. Indeed, posttranscriptional events such as RNA stabilization are important for cell differentiation. MicroRNAs (miRNAs) have emerged as powerful regulators acting at the posttranscriptional level implicated in a wide range of cellular functions. miRNAs are small endogenous RNAs with 20-24 nucleotide length regulating gene expression by base pairing their 2-7 first nucleotides (seed region) with complementary sequences principally located in the 3 ' UTRs of protein-coding transcripts (Lai 2002). Each miRNA can possibly interact with multiple transcripts and the translation of each transcript can be regulated by multiple miRNAs. Bioinformatics' tools using pair-base analyses estimate that one miRNA can recognize several hundreds of predicted targets (Krek et al. 2005). miRNAs have been first known to be implicated in development (Fiore et al. 2008) or oncogenesis (Cho 2007). Furthermore, compelling evidence has demonstrated the substantial regulatory role of miRNAs in energy metabolism and liver functions (Poy et al. 2004, Esau et al. 2006, Plaisance et al. 2006). miRNAs are also implicated in neuronal development, dendritic spine formation, synaptic plasticity (Vo et al. 2005, Schratt et al. 2006, Smalheiser \& Lugli 2009), as well as in the regulation of signaling pathways (Inui et al. 2010). However, little is known concerning the expression profile of miRNAs in the hypothalamus and whether leptin can modulate it in early life. Thus, we hypothesized that leptin blockade early in life may affect hypothalamic miRNA expression pattern leading to a specific phenotype characterized by the predisposition to increased body weight gain associated with leptin and insulin resistance.

Here, we investigated the impact of pegylated rat leptin antagonist (pRLA) treatment (from d2 to d13) on body weight gain and insulin/leptin resistance at both hypothalamic and peripheral levels, as well as the effect on the expression profile of hypothalamic miRNAs.

\section{Materials and methods}

\section{Animals}

Twenty one-mated Wistar rats aged 8 weeks were purchased from Janvier (Le Genest-St-Isle, France) at the stage of $\mathrm{d} 15$ of gestation. They were housed individually in fixed conditions of temperature $\left(20-22^{\circ} \mathrm{C}\right)$ and hygrometry (around $40 \%$ ) in a $12 \mathrm{~h}$ light: $12 \mathrm{~h}$ darkness cycle. They had free access to food (standard chow diet) and water. At birth (d0), litters were 11 pups and then were adjusted at ten pups per dams as described previously (Férézou-Viala et al. 2007). All male pups were kept in each litter and the adjustment was made by reducing or increasing the number of female pups. Litters were

Published by Bioscientifica Ltd. 
randomly assigned to the control or treated group. Newborn male rats received a daily s.c. injection of $\mathrm{NaCl}$ $(0.9 \%, n=36,51$, control group) or pRLA ( $7.5 \mu \mathrm{g} / \mathrm{g}$ per day; $n=35,5 \mathrm{l}$, treated group) between 1700 and $1800 \mathrm{~h}$, from $\mathrm{d} 2$ to d13. The dose of pRLA was chosen according to our previous paper (Attig et al. 2008). pRLA was a gift from Protein Laboratories Rehovot Ltd. (Rehovot, Israel). pRLA was prepared from RLA (Salomon et al. 2006) by monopegylation according to the protocol described by Elinav et al. (2009) for leptin antagonists. It is specific for leptin receptor only and binds to leptin receptors from all mammalian species. Though pegylation reduces pRLA's affinity toward leptin receptor by five- to sixfold, its in vivo activity is much more potent than the non-pegylated RLA due to its highly prolonged half-life in circulation (A Gertler and G Solomon, unpublished data). After weaning (d28), rats of both groups were fed ad libitum with a standard chow diet $(377 \mathrm{kcal} / 100 \mathrm{~g}$; energy derived from carbohydrates, 68.5\%; from lipids, $11.9 \%$; and from proteins, 19.6\%; formula 113, Safe, Augy, France) and had free access to water. Then, from d125 to d153, all rats were challenged ad libitum with an unpalatable high-fat diet (HFD; $439.7 \mathrm{kcal} / 100 \mathrm{~g}$; energy derived from carbohydrates: $38.5 \%$; from lipids: $46 \%$; and from proteins $15.5 \%$; formula 235 HF, Safe) (Fig. 1A). HFD was replaced every 2 days. All procedures were conducted according to the guidelines of laboratory animal care and were approved by the local governmental commission for animal research: Ethic Committee for animal experimentation of PARIS Center and South\# 59 (FRANCE), with authorization \# 91-519.

\section{Metabolic and endocrine measures}

Body weights were daily measured from $\mathrm{d} 2$ to $\mathrm{d} 15$ and then once a week. Food intake and body length were measured once a week from weaning (d28) to the end of the experiment. BMI was calculated as the ratio of body weight $(\mathrm{g})$ :body length $(\mathrm{cm})^{2}$.

At d28, d90, or d153, fasted (4 h) control and pRLA rats were anesthetized with isoflurane $(<5 \mathrm{~min}$ in order to avoid any negative impact on measured parameters (Hamaya et al. 2000, Takamura et al. 2008) before killing. Liver and abdominal adipose tissues were weighted. Blood was collected in heparinized tubes (Lovenox, $200 \mathrm{IU} / \mathrm{ml}$ ), centrifuged (1500 $\boldsymbol{g}$ during $30 \mathrm{~min})$, and plasma were stored at $-20^{\circ} \mathrm{C}$. Plasma glucose levels were measured with glycemia kit (Accu-Chek Performa); leptinemia, insulinemia, and adiponectinemia were quantified using ELISA kits (Millipore, Molsheim, France) according to the manufacturer's instructions. Homeostasis model
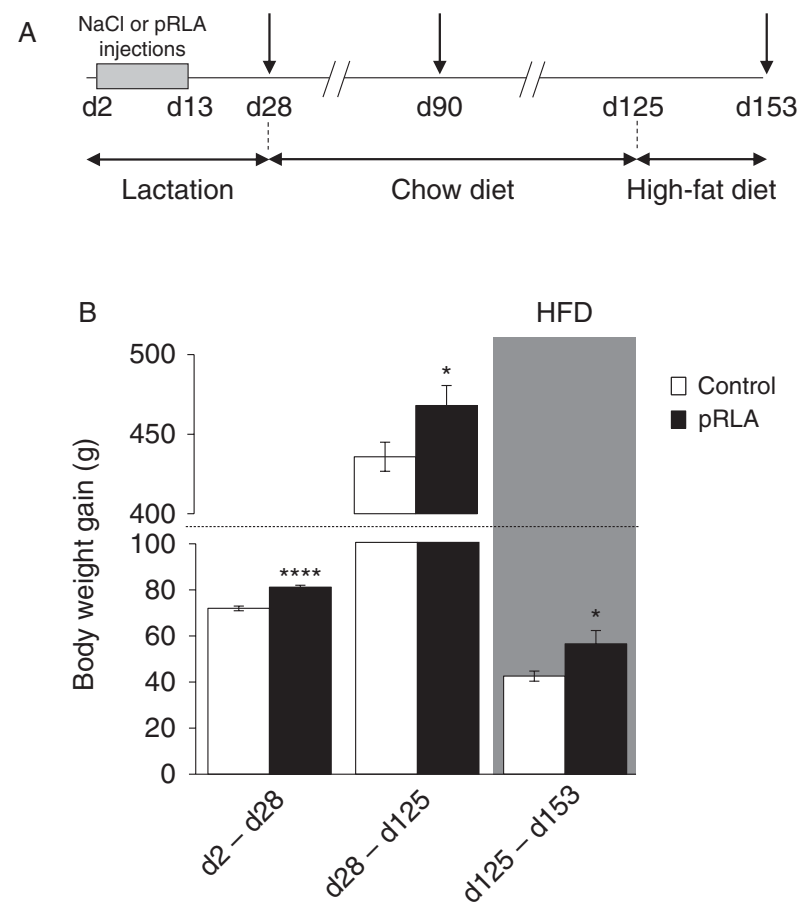

Figure 1

(A) Experimental design. Rats received a daily i.p. injection of $\mathrm{NaCl}$ or pRLA from $\mathrm{d} 2$ to $\mathrm{d} 13$. Both groups were weaned at $\mathrm{d} 28$ with a chow diet and challenged with a HFD from d125 to d153. Rats were killed at d28, d90, or d153 (vertical arrows). (B) Effect of the postnatal leptin blockade on the body weight gain during lactation, chow diet, and after 1-month challenge with HFD. Rats were divided into two groups at birth and daily injected with $\mathrm{NaCl}$ (control group, open bars) or leptin antagonist (pRLA group, dark bars). Both groups were weaned at $\mathrm{d} 28$ with a chow diet and challenged with a HFD from d125 to d153. Body weights were measured each day during postnatal injections and then once a week until the end of the experiment. Body weight gain after postnatal injections (d2-d28), under chow (d28-d125), and high-fat (d125-d153) diets are presented. The results are expressed as mean \pm s.E.M. $n=35$ per group from d2 to $\mathrm{d} 28, n=30$ per group from d 28 to $d 90$, and $n=15$ per group from d90 to d 153 . $* P<0.05, * * * * P<0.0001$ compared with control.

assessment (HOMA) index was calculated following the formula: HOMA index $=($ blood glucose $(\mathrm{mg} / \mathrm{dl}) \times$ insulin $(\mu \mathrm{U} / \mathrm{ml})) / 405$.

\section{Protein analysis}

Liver and hypothalamus of 90-day-old ( $n=5$ per group) and 153-day-old ( $n=5$ per group) rats were quickly removed and frozen in liquid nitrogen and stored at $-80^{\circ} \mathrm{C}$. Samples were homogenized in $1 \mathrm{ml}$ lysis buffer (10 mM Tris- $\mathrm{HCl}$ (pH 7.5), $150 \mathrm{mM} \mathrm{NaCl}, 1 \mathrm{mM}$ EGTA, $1 \mathrm{mM}$ EDTA, $0.5 \%$ nonidet-P40, $1 \%$ Triton X-100, protease inhibitor cocktail $(0.35 \mathrm{mg} / \mathrm{ml}$ phenylmethylsulphonyl fluoride, $2 \mathrm{mg} / \mathrm{ml}$ leupeptin, and $2 \mathrm{mg} / \mathrm{ml}$ aprotinin), and phosphatase inhibitor cocktail $(10 \mathrm{mM}$ sodium

Published by Bioscientifica Ltd 
fluoride, $1 \mathrm{mM}$ sodium orthovanadate, $20 \mathrm{mM}$ sodium $\beta$-glycerophosphate, and $10 \mathrm{mM}$ benzamidine) with Precellys 24/Cryolys (hypothalamus: 20 s; liver: $2 \times 20$ s). Homogenates were incubated for $2 \mathrm{~h}$ at $4{ }^{\circ} \mathrm{C}$ and then centrifuged $\left(1 \mathrm{~h}\right.$ at $14000 \mathrm{~g}$ at $\left.4{ }^{\circ} \mathrm{C}\right)$ and supernatants were stored at $-80^{\circ} \mathrm{C}$. Protein concentrations of supernatants were determined using a protein assay kit (BCA Protein Assay Kit, Thermo Scientific, Courtaboeuf, France).

Leptin sensitivity was assessed by the measurement of leptin-dependent phosphorylation of ERK1/2 in the liver at d90. Control and pRLA-treated rats received an i.p. injection of recombinant rat leptin $(1 \mathrm{mg} / \mathrm{kg} ; n=5$ per group) or $\mathrm{NaCl} 0.9 \%$ ( $n=5$ per group) $30 \mathrm{~min}$ before killing.

Proteins $(70 \mu \mathrm{g})$ were subjected to SDS-PAGE and transferred onto nitrocellulose membranes. Blots were blocked with 3\% BSA and then incubated in the presence of anti-pERK1/2, anti-p-JNK, or anti-PTP1B for liver extracts, whereas hypothalamus blots were incubated with antibodies directed toward PTP1B, SOCS-3, JAK-2, or IRS-2. Membranes were then incubated with the appropriate secondary antibody and targeted proteins were revealed using enhanced chemiluminescence reagents (ECL, Amersham Life Science). The intensity of bands was determined using Carestream apparatus. Relative protein quantities were normalized using anti-tERK1/2, anti-t-JNK, or anti- $\beta$-tubulin antibodies.

\section{In vitro insulin stimulation on liver membranes}

Liver $(500 \mu \mathrm{g})$ from control and pRLA of 153-day-old rats were homogenized in buffer A $(0.32 \mathrm{M}$ sucrose, $2 \mathrm{mM}$ HEPES, $\mathrm{pH} 7.4$, and protease and phosphatase inhibitor cocktail) with tissue homogenizer (Precellys $24 /$ Cryolys). Homogenates were then diluted at $10 \% \mathrm{w} / \mathrm{v}$ in buffer $\mathrm{A}$ and centrifuged $\left(5 \mathrm{~min}\right.$ at $1000 \mathrm{~g}$ at $4^{\circ} \mathrm{C}$ ). Supernatants were kept and pellets were re-suspended in buffer $A$ and centrifuged ( $5 \mathrm{~min}$ at $1000 \mathrm{~g}$ at $4{ }^{\circ} \mathrm{C}$ ). The two supernatants were mixed and centrifuged $(20 \mathrm{~min}$ at $1000 \boldsymbol{g}$ at $4{ }^{\circ} \mathrm{C}$ ). Pellets were then re-suspended in lysis buffer B ( $2 \mathrm{mM}$ HEPES, pH 7.4, $50 \mu \mathrm{M} \mathrm{Ca}^{2+}$, and protease and phosphatase inhibitor cocktail, incubated for $30 \mathrm{~min}$ at $4{ }^{\circ} \mathrm{C}$ and centrifuged $\left(20 \mathrm{~min}\right.$ at $20000 \mathrm{~g}$ at $\left.4{ }^{\circ} \mathrm{C}\right)$. Pellets, representing crude liver membranes, were suspended in buffer $\mathrm{C}\left(50 \mathrm{mM}\right.$ Tris-HCl, $\mathrm{pH} 7.4,1 \mathrm{mM} \mathrm{MgCl}_{2}$, $2 \mathrm{mM}$ EGTA, and protease and phosphatase inhibitor cocktail) and stored at $-80^{\circ} \mathrm{C}$. Protein concentrations of the resulting lysates were determined using a protein assay kit (BCA Protein Assay Kit, Thermo Scientific).

Crude liver membranes $(50 \mu \mathrm{g})$ were incubated for $10 \mathrm{~min}$ at $37^{\circ} \mathrm{C}$ with insulin $(1 \mu \mathrm{M})$ and ATP $(5 \mathrm{mM})$ or with buffer $\mathrm{C}$ as control. Reaction was stopped by the addition of loading buffer. Western blots were performed as described earlier, using an anti-phosphotyrosine, an anti- $\beta$-insulin receptor, and an anti-IRS- 1 antibody.

\section{RNA analysis}

Skeletal muscle, liver, adipose tissue, and hypothalamus of 28- ( $n=4$ per group), 90- ( $n=5$ per group), or 153 - $(n=5$ per group) day-old rats were quickly removed in RNAsefree conditions, immediately frozen into liquid nitrogen, and stored at $-80^{\circ} \mathrm{C}$. Frozen samples of muscle, liver, adipose tissue, and hypothalamus were homogenized using tissue homogenizer (Precellys 24/Cryolys) and RNA was extracted using TRIzol LS reagent (Invitrogen) according to the manufacturer's recommendations. RNAs $(1 \mu \mathrm{g})$ were reverse transcribed (F-572L M-Mulv, Finnzymes, Fontenay-sous-bois, France) and subjected to real-time PCR (Step-One, Applied Biosystems) using adequate primers and Fast SyberGreen Master Mix (Applied Biosystems). Relative cDNA quantities were calculated from cycle thresholds (Ct) and normalized with the housekeeping gene $S 18$ (Rps18) using the $2-\Delta \Delta C \mathrm{t}$ method (Livak \& Schmittgen 2001).

\section{miRNA analysis}

Pooled hypothalamic total RNA from control and pRLA 28-day-old rats $(n=4)$ was analyzed using Taqman Low Density Array (TLDA, TaqMan Array Rodent miRNA A + B Card Set v2.0, Applied Biosystems). Briefly, RNA (900 ng) was reverse transcribed using random primers and the High Capacity cDNA Archive Kit. Then, the resulting cDNAs were subjected to qPCR according to the manufacturer's recommendations. miRNA expression was calculated according to the geometric mean of the 21 miRNAs with the lowest variation among the control and treated conditions. Only miRNAs presenting a fold change expression of at least $1.5(>1.5$ or $<0.66)$ in pRLA rats compared with control and having a $\mathrm{Ct}$ inferior to 32 were selected for further analyses.

To validate miRNAs identified by TLDA methodology, quantitative real-time PCR was performed for selected miRNAs for each animal. Briefly, RNA ( $5 \mathrm{ng}$ ) was reverse transcribed using miRNA-specific RT primers (TaqMan MicroRNA Assay, Applied Biosystems) and reagents from the TaqMan MicroRNA Reverse Transcription Kit according to the manufacturer's instructions. Then, miRNAs were amplified using a specific miRNA TM primer (TaqMan MicroRNA Assay) and TaqMan Universal PCR

Published by Bioscientifica Ltd. 
Master Mix (Applied Biosystems). Relative expression levels were calculated from cycle thresholds and normalized with the housekeeping gene U87 (Snord 87) using the $2-\Delta \Delta C$ t method (Livak \& Schmittgen 2001).

\section{Hormones, western blot antibodies, and qPCR primers}

pRLA is a mutated leptin that has conserved the ability to bind leptin receptors without inducing leptin signaling (pRLA; L39A/D40A/F41A). pRLA and recombinant rat leptin were produced as described previously (Salomon et al. 2006, Elinav et al. 2009). Human insulin was purchased from Sigma.

Antibodies anti-p-ERK1/2, t-ERK1/2, p-JNK, t-JNK, IR- $\beta$, IRS- 1 , and $\beta$-tubulin were purchased from Cell Signaling Technologies (Danvers, MA, USA); the antiphosphotyrosine $4 \mathrm{G} 10$ was purchased from Upstate (Millipore, France); the anti-PTP1B and anti-SOCS-3 were purchased from Santa Cruz Biotechnology. Secondary antibodies (from mouse and rabbit) conjugated to peroxidase were purchased from Sigma-Aldrich.

miRNA primers were purchased from Applied Biosystems and mRNA primers from Sigma-Aldrich. The PCR primer sequences used were as follows: UCP2 forward: 5'-TGGCGGTGGTCGGAGATAC-3' , reverse: 5'-GGCAAGGGAGGTCGTCTGTC-3'; UCP3 forward: 5'-CCCAAAGG AACGGACCAC-3', reverse: 5'-GGTTCTGTAGGCATCCATAGTC-3'; AdipoR1 forward: 5'-GCTGGCCTTTATGCTG CTCG-3', reverse: 5'-TCTAGGCCGTAACGGAATTC-3'; AdipoR2 forward: 5'-CCACAACCTTGCTTCATCTA-3', reverse: 5'-GATACTGAGGGGTGGCAAAC-3'; OBRa forward: 5'-TTTCCAAAAGAGAGCGGACAC-3', reverse: 5'-AGGTTGGTAGATTGGATTCATC-3'; OBRb forward: 5'-ACСACATACСТССТСАСАСТA-3', reverse: 5'-AGCAG TCCAGCCTACACTCTT-3'; IR forward: 5'-TGCCACCAATCCTTCCGTTCC-3', reverse: 5'-TCCTCCGCCTG CСТCTCC-3'; PTP1B forward: 5'-GCACAGCATGAGCAG TATGAG-3', reverse: $5^{\prime}$-TCCACCCACCATCCGTTTCC-3'; NPY forward: 5'-ATGCTAGGTAACAAACG-3', reverse: 5'-ATGTAGTGTCGCAGAG-3'; POMC forward: 5'-AGG TTAAGGAGCAGTGACTAAG-3', reverse: $5^{\prime}$-CGTCTATGG AGGTCTGAAGC-3'; IL6 forward: 5'-GTTGCCTTCTTGGG ACTGATGTT- ${ }^{\prime}$, reverse: $5^{\prime}$-ACTGGTCTGTTGTGGGTGG TATC-3'; NF- $\kappa$ B forward: 5'-GCGACAGATGGGCTACACAGAGG-3', reverse: 5'-TGGAGGAGGACGAGAGAGG CA-3'; TNF $\alpha$ forward: 5'-CTCATTCCTGCTCGTGGCGG-3', reverse: 5'-CCGCTTGGTGGTTTGCTACGA-3'; S18 forward: 5'-TCCCCGAGAAGTTTCAGCACAT-3', reverse: 5'-CTTCCCATCCTTCACGTCCTTC-3'.

\section{Statistical analysis}

Statistical analyses were performed using Mann-Whitney $U$ test for endocrine parameter data, signaling, and gene expression experiments. A repeated-measures two-way ANOVA was used to test changes in body weight and energy intake over time followed by Bonferroni post hoc test. Linear regression between insulinemia and glycemia was calculated with values of each animal. The results are expressed as mean \pm s.E.M. and $P<0.05$ was considered as statistically significant.

\section{Results}

\section{Postnatal treatment with leptin antagonist increases body weight gain}

Body weight gain was determined in three stages: from $\mathrm{d} 2$ to weaning (d28), from weaning to $\mathrm{d} 125$, and finally during the HFD challenge (from d125 to d153). In all stages, pRLA rats exhibited a significantly higher body weight gain with $+17.8 \%(P<0.0001),+7.4 \%(P<0.05)$, and $+32.8 \% \quad(P<0.05)$ increase between $\mathrm{d} 2-\mathrm{d} 28$, d28-d125, and d125-d153 respectively (Fig. 1B).

\section{Metabolic and endocrine parameters}

The weekly energy intake ( $\mathrm{kcal} / \mathrm{rat}$ ) was similar between pRLA and control groups at weaning but was significantly higher in the pRLA group at $\mathrm{d} 90(P<0.001)$ and $\mathrm{d} 153$ $(P<0.05)$ (Table 1$)$. The body length and BMI were significantly $(P<0.05)$ higher in pRLA group at $\mathrm{d} 28$, but these differences were abolished in adulthood (d90) and after HFD (d153) (Table 1). Abdominal adipose tissue and liver weights were not significantly modified in pRLA rats (data not shown).

Leptinemia, as expected, increased with age in both pRLA and control groups, but no significant differences were found between the two groups (Table 1). By contrast, adiponectin plasma levels were decreased with age in control group $(P<0.01$ between d28-d90 and d90-d153). However, pRLA rats exhibited lower levels of plasma adiponectin compared with control rats at d28 $(P<0.05)$ and d90 $(P<0.01)$ but not after HFD challenge (d153) (Table 1). Insulinemia was significantly increased in pRLA rats at d90 $(P<0.05)$ with a high HOMA index (Table 1$)$. Finally, glycemia was similar between pRLA and control rats (Table 1). Considering the coefficient of determination $R^{2}$, insulinemia and glycemia were correlated in control

Published by Bioscientifica Ltd. 
Table 1 Metabolic and endocrine parameters measured in control and pRLA rats at weaning (d28), under chow diet (d90), and after 1-month challenge with HFD (d153)

\begin{tabular}{l} 
Metabolic parameters \\
$n$ \\
Body weight (g) \\
WEI (kcal/rat) \\
Body length $(\mathrm{cm})(n)$ \\
BMI (g/cm²) $(n)$ \\
Endocrine parameters \\
$n$ \\
Leptinemia (ng/ml) \\
Adiponectinemia $(\mu \mathrm{g} / \mathrm{ml})$ \\
Insulinemia $(\mathrm{ng} / \mathrm{ml})$ \\
Glycemia $(\mathrm{mg} / \mathrm{ml})$ \\
HOMA index \\
LR $\left(R^{2} / P \text { value }\right)^{\mathrm{c}}$ \\
\hline
\end{tabular}

\begin{tabular}{c} 
At wean \\
\hline Control \\
\hline \\
36 \\
$82.4 \pm 1.3$ \\
$331 \pm 14$ \\
$14 \pm 0.1(16)$ \\
$0.403 \pm 0.005$
\end{tabular}

(16)

\begin{tabular}{c}
5 \\
$5.22 \pm 0.88$ \\
$34.1 \pm 2.2$ \\
$0.87 \pm 0.13$ \\
$230 \pm 21.3$ \\
$2.16 \pm 0.31$ \\
$0.73 / 0.06$ \\
\hline
\end{tabular}

WEI, weekly energy intake. ${ }^{\dagger} P<0.01 ;{ }^{\ddagger} P<0.0001$.

${ }^{a}$ Difference between control and pRLA rat at one stage.

bifference between the same group at the three stages d28, d90, and d153.

'Linear regression between insulinemia and glycemia, calculated with values of each animal.

\begin{tabular}{|c|c|c|c|}
\hline \multicolumn{2}{|c|}{ Under chow diet (d90) } & \multicolumn{2}{|c|}{ Under HFD (d153) } \\
\hline Control & pRLA & Control & pRLA \\
\hline $\begin{array}{c}16 \\
451.4 \pm 5.7 \\
593 \pm 6 \\
26.4 \pm 0.3(5) \\
0.623 \pm 0.008 \\
(5)\end{array}$ & $\begin{array}{c}16 \\
465.1 \pm 8.4 \\
663 \pm 15^{\mathrm{a}} \\
26.7 \pm 0.5(5) \\
0.66 \pm 0.025(5)\end{array}$ & $\begin{array}{c}15 \\
559.2 \pm 9.2 \\
542 \pm 13 \\
27.6 \pm 0.2(5) \\
0.717 \pm 0.016 \\
(5)\end{array}$ & $\begin{array}{c}14 \\
603.4 \pm 20.2^{a} \\
604 \pm 17^{\mathrm{a}} \\
29 \pm 0.5(4) \\
0.729 \pm 0.015 \\
(4)\end{array}$ \\
\hline $\begin{array}{c}5 \\
12.19 \pm 1.06 \\
23.3 \pm 0.7^{b} \\
0.33 \pm 0.26 \\
206 \pm 6.5 \\
3.29 \pm 0.65 \\
0.88 /<0.01\end{array}$ & $\begin{array}{c}5 \\
15.58 \pm 2.19 \\
19.0 \pm 1.0^{\dagger} \\
2.53 \pm 0.39^{a} \\
208.8 \pm 3.3 \\
6.24 \pm 0.97^{a} \\
0.42 / 0.23\end{array}$ & $\begin{array}{c}5 \\
17.21 \pm 1.79 \\
16.7 \pm 1.4^{b} \\
0.08 \pm 0.03 \\
156.2 \pm 2.3 \\
0.19 \pm 0.07 \\
0.005 / 0.89\end{array}$ & $\begin{array}{c}5 \\
23.21 \pm 3.89 \\
20.3 \pm 2.0 \\
0.24 \pm 0.13 \\
149.6 \pm 6.8 \\
0.59 \pm 0.29 \\
0.16 / 0.49\end{array}$ \\
\hline
\end{tabular}

rats at $\mathrm{d} 28\left(R^{2}=0.73\right)$ and $\mathrm{d} 90\left(R^{2}=0.88\right)$, whereas no correlation was detected in pRLA rats $\left(\mathrm{d} 28: R^{2}=0.28\right.$ and d90: $R^{2}=0.42$ ). Under HFD, correlation was lost in both control $\left(R^{2}=0.005\right)$ and pRLA rats $\left(R^{2}=0.16\right.$; Table 1$)$.

\section{Impact of postnatal leptin blockade on insulin and leptin signaling pathways}

As pRLA treatment significantly affected insulinemia, HOMA index, and body weight gain, we investigated signaling pathways involving both leptin and insulin. Leptin treatment significantly $(P<0.01)$ increased liver ERK1/2 phosphorylation in control rats but not in pRLA rats at $\mathrm{d} 90$ (Fig. 2A). We also tested the liver insulin sensitivity after HFD (d153) in both pRLA and control rats in vitro using crude liver membranes. Insulin clearly induced the protein tyrosine phosphorylation in control but to a lesser extent in pRLA rats. Two of the insulininduced phosphorylated proteins correspond to IRS- 1 and the $\beta$-subunit of insulin receptor as evidenced by immunoblots using antibodies directed toward these two proteins (Fig. 2B). Following HFD challenge, liver JNK phosphorylation was increased in pRLA rats compared with controls $(P<0.001$, Fig. 2C), but PTP1B (PTPN1) expression was not significantly modified (Fig. 2D).

To further investigate the insulin and leptin sensitivity, we determined at $\mathrm{d} 90$ the expression levels of PTP1B and SOCS3 in the hypothalamus of both groups. PTP1B
$(P<0.05$, Fig. 2E) and SOCS3 $(P<0.05$, Fig. $2 \mathrm{~F})$ were upregulated in pRLA rats compared with control rats.

\section{Postnatal leptin blockade affects the expression of genes involved in the control of energy homeostasis}

To investigate whether leptin blockade in early life affects genes involved in the control of energy homeostasis, the expression of several genes was studied in muscle, liver, adipose tissue, and hypothalamus. In muscle, pRLA treatment significantly increased Ucp2 $(P<0.05)$ and Ucp3 $(P<0.01)$ expression levels at d90 as well as Adipor1 $(P<0.05)$ and Adipor2 $(P<0.05$; Fig. 3A, B, C, and D). However, following HFD, the expression of Adipor2 was decreased $(P<0.05)$ in the pRLA group compared with control rats (Fig. 3D). In liver, the expression of Adipor1 and Adipor 2 was significantly $(P<0.05)$ increased in pRLA rats compared with control rats following HFD (d153) but remained unchanged at $\mathrm{d} 28$ and $\mathrm{d} 90$ (Figs $3 \mathrm{~F}$ and $4 \mathrm{E}$ ). In adipose tissue, pRLA treatment significantly reduced the expression of insulin receptor $(P<0.05)$ at d153 (Fig. 3G).

In the hypothalamus, the expression of both short (OBRa) and long (OBRb) isoforms of leptin receptor, insulin receptor, and Adipor2 was significantly $(P<0.05)$ increased in pRLA rats at d28 but not at d90 or d153 (Fig. 4A, B, C, and E). The expression of PTP1B was significantly $(P<0.05)$ increased at $\mathrm{d} 90$ in the pRLA group (Fig. 4D). 

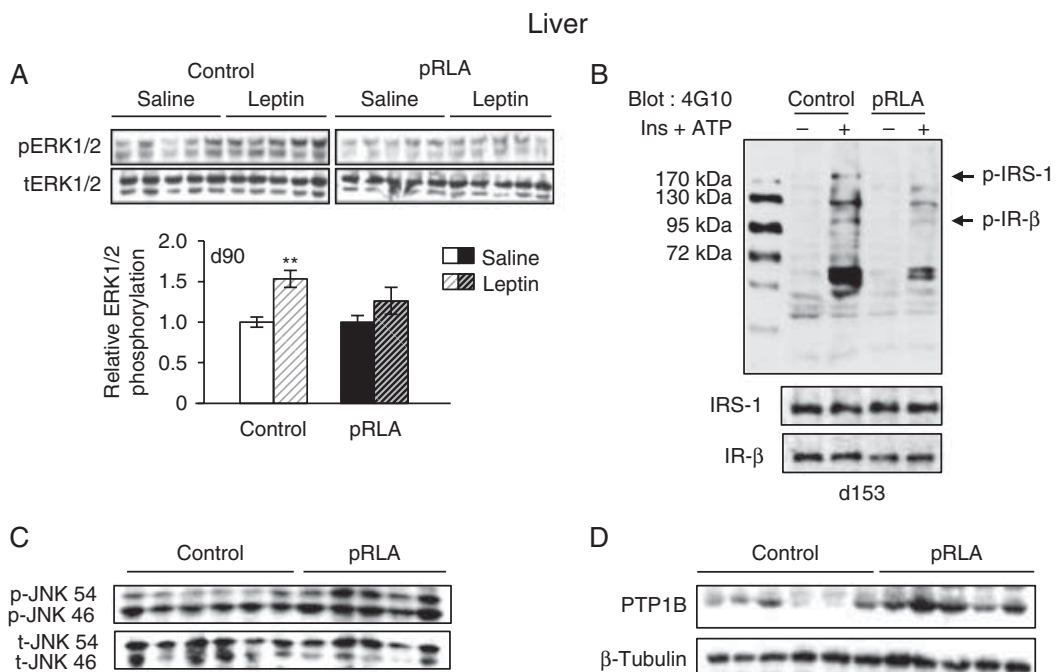

D
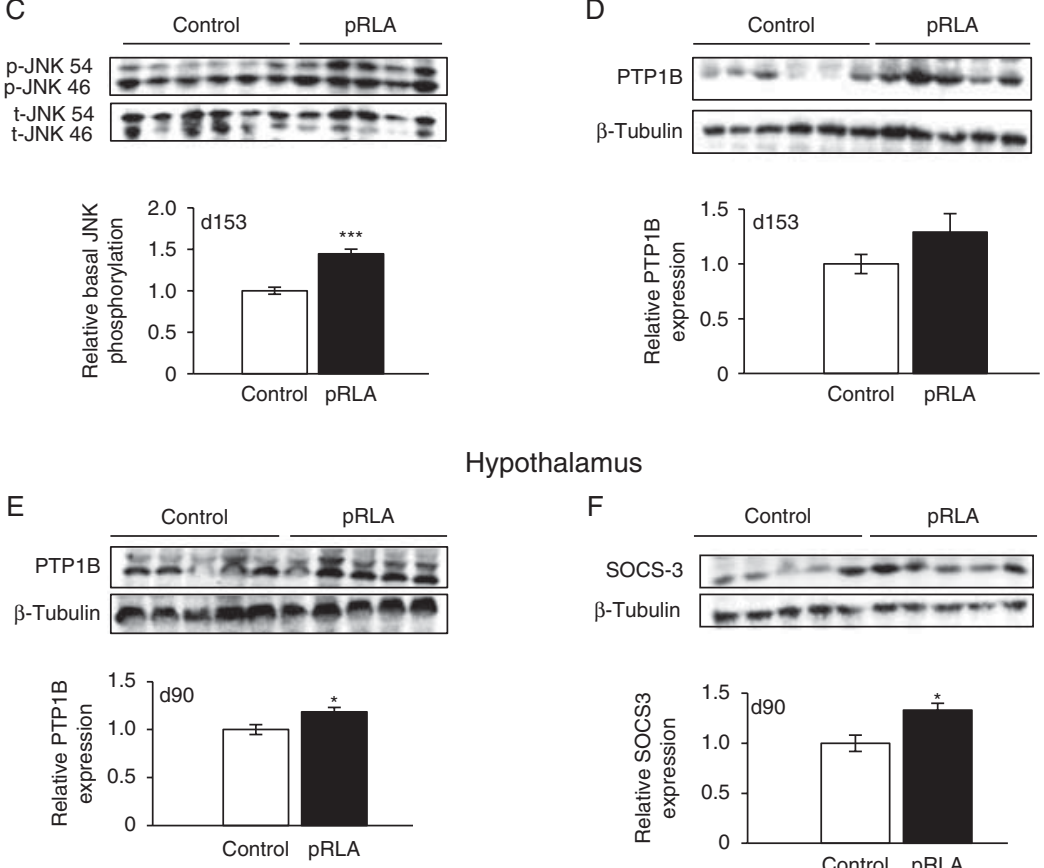

Hypothalamus

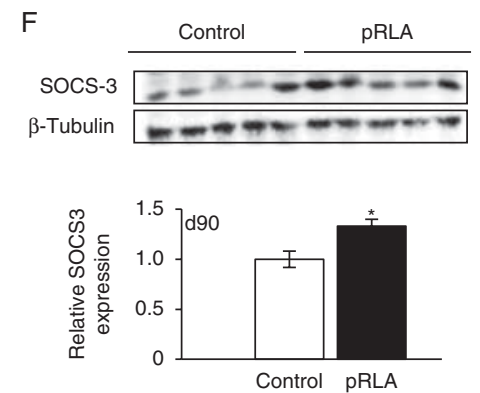

Figure 2

Postnatal leptin blockade decreases leptin and insulin sensitivity. (A) 90-dayold control and pRLA rats were injected intraperitoneally $30 \mathrm{~min}$ before killing with either saline or leptin $(1 \mathrm{mg} / \mathrm{kg}$ ) and liver ERK $1 / 2$ phosphorylation was assessed. Leptin efficiency on ERK1/2 phosphorylation related to total-ERK $1 / 2$ is expressed as percentage of $\mathrm{NaCl}$-injected group.

(B) Phosphotyrosine profiles after stimulation with $\mathrm{NaCl}$ or insulin $(1 \mu \mathrm{m})+$ ATP ( $5 \mathrm{mM}$ ) of crude liver membranes of 153-day-old rats. Protein quantities

\section{Distinctive miRNA expression patterns in the hypothalamus of pRLA-treated rats}

To investigate the impact of leptin blockade on hypothalamic miRNA expression pattern, we have performed at d28 a large-scale expression analysis using TLDA methodology to analyze 524 rat mature miRNAs and miRNA-related sequences in pRLA rats compared with controls. As shown in Table 2, the relative expression of 38 out of 524 miRNAs was modified in the hypothalamus were verified with anti- $\beta$-insulin receptor and anti-IRS-1 antibodies. (C) Relative basal phosphorylation of JNK in the liver of 153-day-old control and pRLA rats. (D) Relative basal expression of PTP1B protein in liver of 153-day-old rats. (E) Relative basal expression of PTP1B protein in hypothalamus of 90-day-old rats. (F) Relative basal expression of SOCS3 protein in the hypothalamus of 90-day-old rats. The results are expressed as mean + S.E.M. ${ }^{*} P<0.05, * * P<0.01, * * * P<0.001$ compared with control.

with a fold change of 1.5 when comparing pRLA to control rats. In particular, 34 miRNAs were upregulated and four miRNAs were downregulated in the hypothalamus of pRLA rats at $\mathrm{d} 28$.

We have selected five miRNAs, based on their predictive targets that have a potential metabolic role, for qRT-PCR validation in the hypothalamus of rats at $\mathrm{d} 28$. To test whether pRLA has a long-term impact on miRNA expression, we analyzed these miRNAs at d90 and d153. 


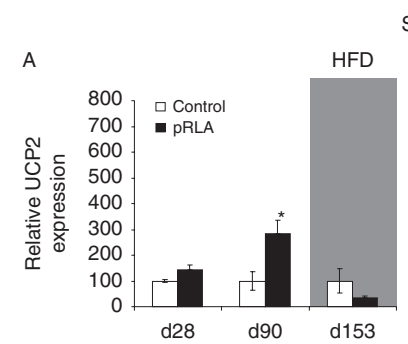

Skeletal muscle
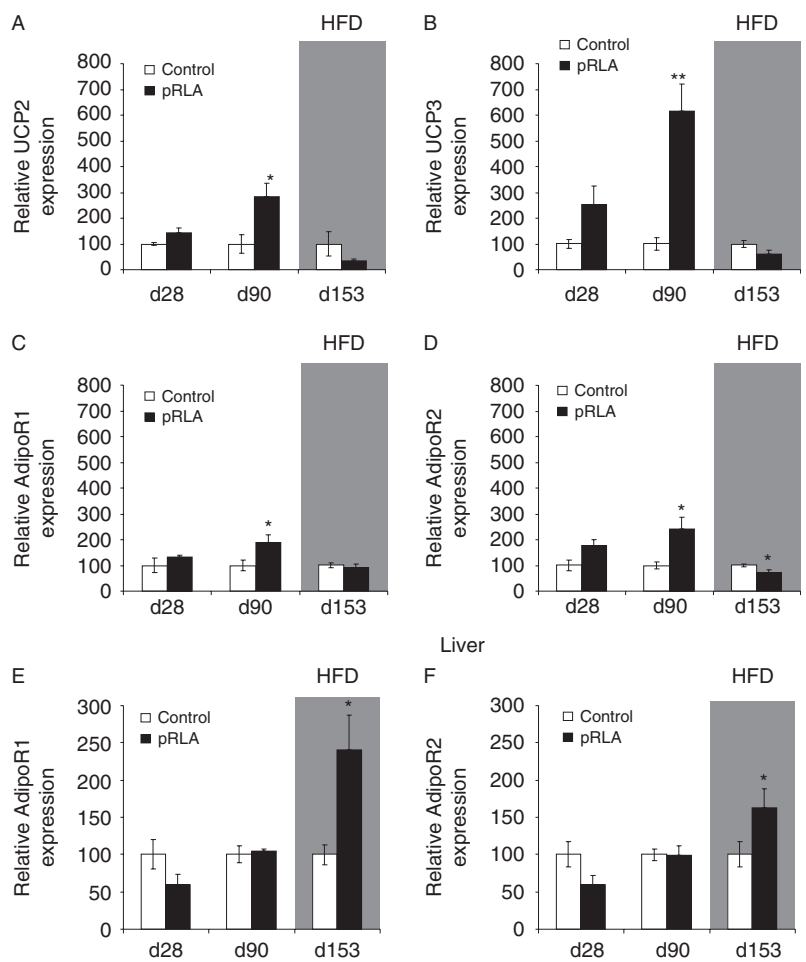

Liver
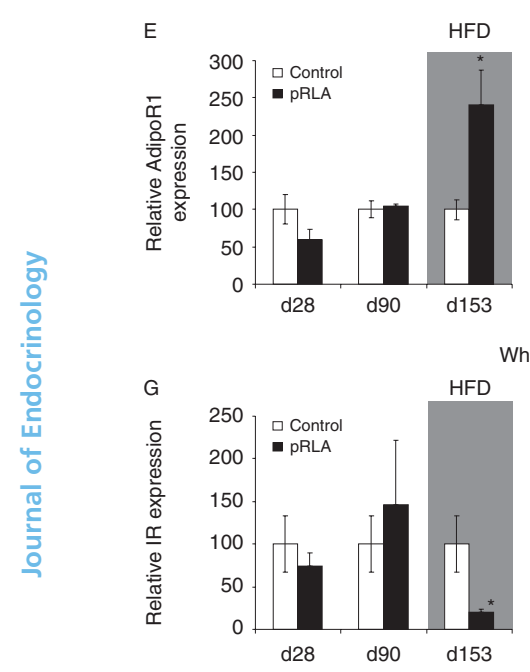

White adipose tissue
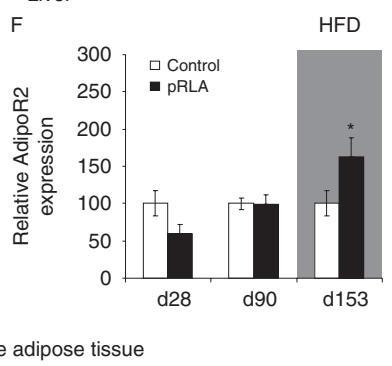

Figure 3

Impact of the postnatal leptin blockade on mRNA expression in peripheral tissues. At d28, d90, and d153, mRNA expression was measured by quantitative RT-PCR in skeletal muscle ( $A, B, C$, and D), liver ( $E$ and F), and peri-renal white adipose tissue $(G)$. Results were normalized to ribosomal S18 mRNA levels. The results are expressed as mean \pm s.E.M. $n \geq 4$ per group, ${ }^{*} P<0.05,{ }^{*} P<0.01$ compared with control.

At $\mathrm{d} 28$, the expression of miR-10a was significantly $(P<0.05$, Fig. $5 \mathrm{~A})$ increased in pRLA rats compared with controls whereas miR-200a (Fig. 5B), miR-409-5p (Fig. 5C), and miR-125a-3p (Fig. 5D) were not significantly increased. At d90, miR-200a was significantly reduced $(P<0.05)$ in pRLA rats whereas miR-10a, miR-409-5p, and miR-125a-3p were not modified. The downregulation of miR-200a is in good agreement with the upregulation of PTP1B (Fig. 4D), as PTP1B is one of the potential miR-200a targets. Following HFD challenge (d153), miR-200a, miR409-5p, and miR-125a-3p were significantly $(P<0.05)$ upregulated in pRLA but not miR-10a. The upregulation of miR-200a and miR-125a-3p is in good agreement with the downregulation of IRS-2 (Fig. 6A) and Jak-2 (Fig. 6B) respectively, known as potential targets according to TargetScan (Calbridge, MA USA) and DNA Intelligent analysis micro-T3 softwares (Athens, Greece).

\section{Discussion}

An adverse hormonal and metabolic environment during the early postnatal period has long-term consequences on energy homeostasis control promoting metabolic disorders including insulin resistance and obesity (Toste et al. 2006, Attig et al. 2008, Kirk et al. 2009). In this study, we report an increase in body weight gain associated with insulin resistance and changes in hypothalamic miRNA expression profile as a consequence of an early postnatal leptin blockade.

Leptin antagonist treatment from $\mathrm{d} 2$ to $\mathrm{d} 13$ durably impaired energy homeostasis as evidenced by higher body weight gain of pRLA rats compared with controls when fed chow diet. This effect was exacerbated following HFD challenge, indicating that postnatal leptin alteration predisposes to excessive body weight gain when animals
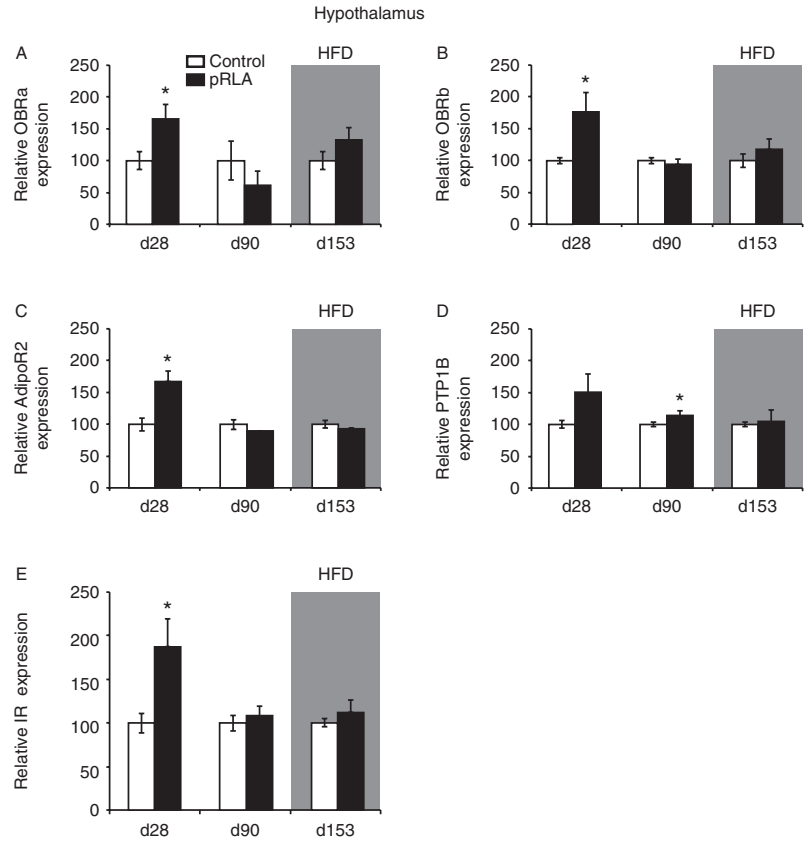

\section{Figure 4}

Impact of the postnatal leptin blockade on mRNA expression in the hypothalamus. Panels A, B, C, D and E show changes in the expression levels of ObRa, ObRb, AdipoR2, PTP-1B and IR, respectively. At d28, d90, and d153, mRNA expression was measured by quantitative RT-PCR. Results were normalized to ribosomal $\$ 18$ mRNA levels. The results are expressed as mean \pm s.E.M. $n \geq 4$ per group, ${ }^{*} P<0.05$, compared with control. 
Table 2 TLDA analysis. Normalized expression of miRNAs upregulated or downregulated in pRLA rats analyzed by TLDA at $d 28$. miRNAs in boldface have been validated by qRT-PCR

\begin{tabular}{|c|c|c|}
\hline & Control & pRLA \\
\hline \multicolumn{3}{|c|}{ Upregulated miRs } \\
\hline miR-200a & 1 & 2.72 \\
\hline miR-125b-3p & 1 & 2.37 \\
\hline $\operatorname{miR}-421$ & 1 & 2.24 \\
\hline miR-493 & 1 & 2.22 \\
\hline miR-1 & 1 & 2.17 \\
\hline miR-182 & 1 & 2.12 \\
\hline miR-10a & 1 & 2.09 \\
\hline miR-125a-3p & 1 & 2.09 \\
\hline miR-20b-5p & 1 & 2.01 \\
\hline miR-28* & 1 & 1.89 \\
\hline $\operatorname{miR}-30 d^{*}$ & 1 & 1.88 \\
\hline $\operatorname{miR}-378^{*}$ & 1 & 1.83 \\
\hline miR-206 & 1 & 1.80 \\
\hline miR-503 & 1 & 1.72 \\
\hline miR-184 & 1 & 1.69 \\
\hline miR-139-3p & 1 & 1.67 \\
\hline $\operatorname{miR}-22 *$ & 1 & 1.65 \\
\hline miR-152 & 1 & 1.64 \\
\hline miR-377 & 1 & 1.64 \\
\hline miR-199a-3p & 1 & 1.62 \\
\hline $\operatorname{miR}-24-2 *$ & 1 & 1.61 \\
\hline miR-448 & 1 & 1.59 \\
\hline miR-222 & 1 & 1.57 \\
\hline miR-879 & 1 & 1.57 \\
\hline $\operatorname{miR}-29 a *$ & 1 & 1.57 \\
\hline miR-190b & 1 & 1.56 \\
\hline miR-203 & 1 & 1.55 \\
\hline miR-489 & 1 & 1.55 \\
\hline miR-379* & 1 & 1.55 \\
\hline miR-409-5p & 1 & 1.54 \\
\hline let-7i* & 1 & 1.54 \\
\hline miR-23b & 1 & 1.52 \\
\hline miR-16 & 1 & 1.52 \\
\hline $\operatorname{miR}-30 e^{*}$ & 1 & 1.51 \\
\hline \multicolumn{3}{|c|}{ Downregulated miRs } \\
\hline miR-344-5p & 1 & 0.65 \\
\hline miR-505 & 1 & 0.61 \\
\hline miR-207 & 1 & 0.60 \\
\hline miR-154 & 1 & 0.57 \\
\hline
\end{tabular}

were fed inappropriate diet as we have previously shown for high palatable diet (Attig et al. 2008). The blockade of leptin action mimics the absence of leptin in the early postnatal period, which is known to deeply alter hypothalamic neural circuitry organization as reported in leptin-deficient $o b / o b$ mice (Bouret et al. 2004a,b). This could, at least partially, explain the impairment of body weight and energy homeostasis controls in pRLA rats. Indeed, postnatal leptin blockade has a significant impact on metabolic and endocrine parameters at adulthood. At d90, this treatment led to insulin resistance as evidenced by hyperinsulinemia associated with increased HOMA index and a lack of correlation between glycemia and insulinemia.
In addition, the plasma levels of adiponectin, considered as an antidiabetic hormone (Kadowaki \& Yamauchi 2005), was significantly reduced in pRLA rats, re-enforcing then the insulin-resistant state.

The hormonal environment of pRLA rats is clearly in favor of an insulin-resistant state known to promote leptin resistance. Indeed, insulin and leptin share several signaling pathways such as JAK-2/STAT-3, IRS/PI3kinase, and ERK1/2 kinase (Carvalheira et al. 2001, Benomar et al. $2005 a, b)$ and cross-desensitization of leptin and insulin signaling pathways has been demonstrated (Benomar et al. 2005a). The phosphotyrosine phosphatase 1B (PTP1B) was identified as a key element in the cross-desensitization between leptin and insulin pathways, as the over-exposure to both hormones led to the upregulation of PTP1B, which in turn dephosphorylates key signaling components such as IRS-1/2 and JAK-2 (Benomar et al. 2009, Berthou et al. 2011).

Following HFD challenge (d153), pRLA rats exhibited liver insulin resistance as supported by reduced insulindependent IR and IRS-1 phosphorylation. In addition, liver JNK phosphorylation in pRLA rats was increased, which is a hallmark of cellular pro-inflammatory state. The phosphorylation of JNK is commonly associated with insulin resistance through the phosphorylation of IRS proteins on serine residues (Aguirre et al. 2000). However, following HFD, other pro-inflammatory markers such as
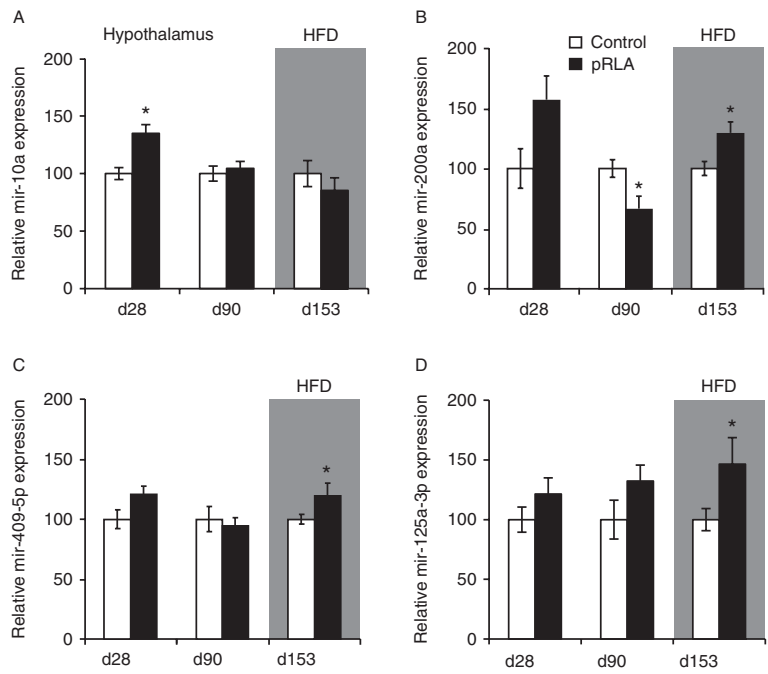

\section{Figure 5}

Impact of the postnatal leptin blockade on hypothalamic miRNA expression. Panels $A, B, C$ and $D$ show changes in the expression levels of mir-10a, mir-200a, mir-409-5p and mir-125a-3p, respectively. At d28, d90, and d153, miRNA expression was measured by quantitative RT-PCR. Results were normalized to $U 87$ levels. The results are expressed as mean \pm S.E.M. $n \geq 4$ per group, $* P<0.05$ compared with control. 
A

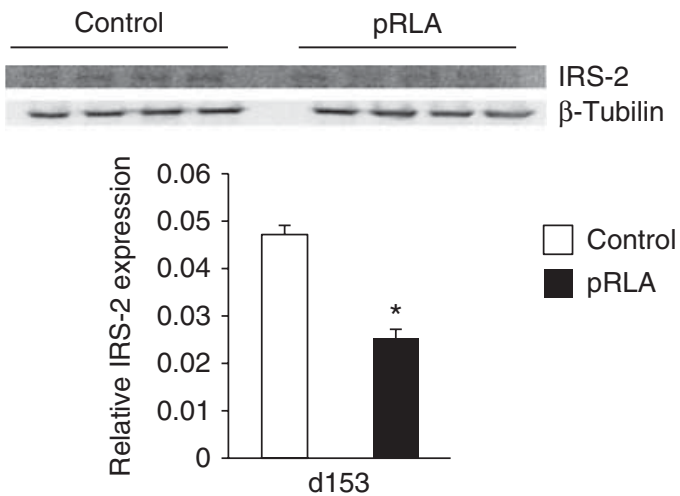

B
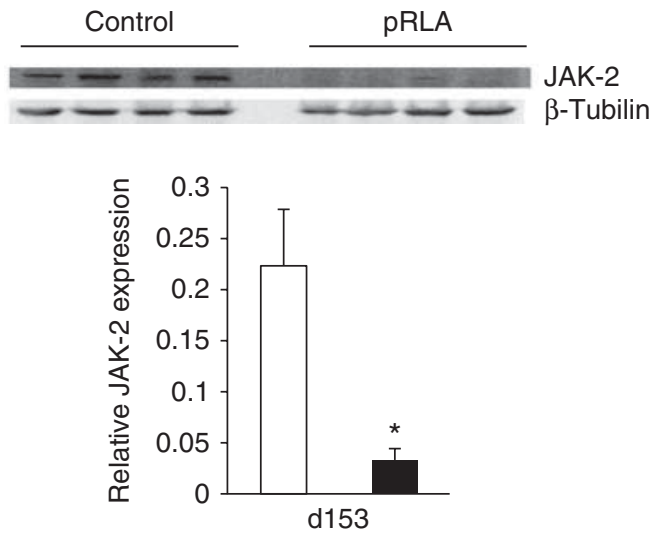

Figure 6

Downregulation of hypothalamic IRS-2 and JAK-2 in pRLA rats following HFD challenge. At d153, IRS-2 (Panel A) and JAK-2 (Panel B) protein expression was measured by western blot using adequate antibodies. The expression level was normalized to $\beta$-tubulin. Band density was measured using Carestream apparatus. The results are expressed as mean \pm s.E.M. $n=4$ per group, $* P<0.05$ compared with control.

TNF $\alpha$, IL6, and NFאB were not affected in pRLA rats at both hypothalamic and hepatic levels (data not shown). It is noteworthy that the impairment of liver insulin responsiveness did not significantly affect liver weight; this could be attributed to the length of HFD challenge period (28 days). Indeed, it has been reported that hypothalamic inflammation markers appeared after 8 weeks of HFD challenge (Calegari et al. 2011). Furthermore, changes in liver weight have been reported in non-alcoholic fatty liver disease subsequently to at least 4 months of HFD challenge (Tsuchiya et al. 2013). Beside the alteration of liver insulin signaling in pRLA rats, we demonstrated that the alteration of leptin signaling in liver was determined by the loss of leptin-dependent ERK1/2 phosphorylation at $\mathrm{d} 90$.

Interestingly, hypothalamic PTP1B and SOCS3 were upregulated in pRLA rats promoting both leptin and insulin resistance, which is in good agreement with our previous findings in human neuroblastoma cell line (Benomar et al. 2009). Additionally, hypothalamic OBRa, $\mathrm{OBRb}$, and AdipoR2 were upregulated in pRLA rats at d28 probably as a consequence of low levels of leptinemia and adiponectinemia. In addition, insulin receptor was also upregulated at $\mathrm{d} 28$ in pRLA rats and this is in good agreement with the downregulation of miR-344-5p (Table 2). Indeed, insulin receptor is a potential target of miR-344-5p according to TragetScan software.

Importantly, early leptin blockade impairs the expression of key genes involved in energy homeostasis control such as UCPs and AdipoRs. Indeed, at d90, muscle $U c p 2$ and $U c p 3$ genes, involved in the regulation of muscle thermogenesis, were upregulated in pRLA rats. This could explain that pRLA and control rats exhibited similar body weight at d90, despite the higher energy intake of pRLA rats through an increase in energy expenditure. This hypothesis is supported by previous studies reporting the upregulation of $U c p 3$ in insulin-resistant fat-fed animals (Samec et al. 1999).

In addition, muscle AdipoRs were upregulated in pRLA at d90 and this led to higher energy expenditure probably through the increase in muscle fatty acid $\beta$-oxidation as previously reported (Yoon et al. 2006). Following HFD challenge, Adipor1 and Adipor2 were upregulated in the liver of pRLA rats, and such upregulations have been reported in type 2 diabetes (Beylot et al. 2006, Metais et al. 2008).

Importantly, our findings brought new insights into the role of leptin in the expression pattern of hypothalamic miRNAs in early life. Postnatal leptin blockade led to the upregulation of 34 miRNAs and the downregulation of four miRNAs in the hypothalamus of d28-old rats. For the quantitative RT-PCR validation, we have focused on four miRNAs: miR-200a, miR-10a, miR-409-5p, and miR-125a-3p that have been strongly linked to metabolic disorders and neuronal differentiation.

In pRLA rats, hypothalamic miR-200a was downregulated at $\mathrm{d} 90$ and upregulated following $\mathrm{HFD}$ challenge. This downregulation is in good agreement with the upregulation of PTP1B, which is a potential target of miR-200a according to miRNA target prediction software (TargetScan). The upregulation of neuronal PTP1B has been linked to the impairment of both insulin and leptin signaling (Benomar et al. 2009). Additionally, metabolic disorders such as diabetes are associated with changes in the expression levels of the miR-200 family at peripheral tissues. Indeed, miR-200a is decreased in the kidney of non-obese diabetic apoE KO mice (Wang et al. 2011) and in the liver of spontaneous diabetic non-obese

Published by Bioscientifica Ltd. 
GK rats (Herrera et al. 2010). Interestingly, miR-200a is increased in liver of obese diabetic ob/ob mice (Li et al. 2009) as well as in liver and pancreatic islets of obese diabetes-resistant B6-ob mice (Zhao et al. 2009). These findings indicate that the expression of miR-200a is decreased with diabetes but is increased in cases of obesity or when diabetes is associated with obesity. In our study, the increase in hypothalamic expression of miR-200a at d153 is associated with a higher body weight gain whereas its decrease at $\mathrm{d} 90$ is associated with insulin resistance as evidenced by a high HOMA index and hypoadiponectinemia. Furthermore, the upregulation of miR-200a at d153 in pRLA rats is in good agreement with the downregulation of hypothalamic IRS-2, a potential target, re-enforcing then the insulin resistance.

Furthermore, hypothalamic miR-125a-3p was upregulated in pRLA rats challenged with HFD, which may explain the strong downregulation of JAK-2 signaling, one of its potential targets. The JAK-2 signaling pathway is involved in both insulin and leptin signaling. Indeed, previous studies have shown that the expression of the miR-125 family is modulated by diabetes. Indeed, miR-125b is upregulated in vascular smooth muscle of diabetic $d b / d b$ mice (Villeneuve et al. 2010) and miR-125a is increased in liver and adipose tissue of diabetic GK rats (Herrera et al. 2009). Moreover, an overexpression of miR-125a and miR-125b led to the alteration of insulin signaling pathways by reducing the insulin-dependent Akt and ERK1/2 phosphorylation in SKBR3 cell line (Scott et al. 2007).

We also report the upregulation of miR-10a in the hypothalamus of pRLA rats at d28. This miRNA is a potent inducer of neuroblastoma and muscle cell differentiation (Huang et al. 2010, Foley et al. 2011, Meseguer et al. 2011). As leptin is involved in neuronal network organization in the hypothalamus, we suggest that blocking leptin action early in life promotes neuronal differentiation instead of proliferation leading to the impairment of energy homeostasis later in life as our findings suggest.

In addition, following HFD challenge, hypothalamic miR-409-5p was upregulated in pRLA rats. According to miRNA target prediction software (TargetScan), protein kinase inhibitor beta (PKIB) is a potential target of miR-409-5p. PKIB is a member of the cAMP-dependent protein kinase inhibitor family that interacts with the catalytic subunit of cAMP-dependent protein kinase and acts as a competitive inhibitor. Thus, the upregulation of miR-409-5p potentially leads to changes in AMPK activity in the hypothalamus that is involved in AdipoR1/AdipoR2 signaling and consequently affects energy homeostasis. It is noteworthy that the direct link between miR-409-5p and AMPK activity needs to be validated in cellular or in in vivo models.

Taken together, our findings indicate that pRLA treatment modified miRNAs in the hypothalamus and these changes occurred at different stages corroborating the long-term impact of early leptin blockade as altered energy homeostasis control and insulin responsiveness. Furthermore, our study emphasizes the complexity of the mechanisms linking changes in hypothalamic miRNA expression pattern to overall insulin resistance and energy homeostasis regulation. Thus, to deeply dissect this relationship, more intensive studies are needed in this field to potentially link the modulation of hypothalamic miRNAs pattern with the predisposition to overall insulin resistance.

In conclusion, we demonstrate that the blockade of leptin action early in life affects i) leptin and insulin signaling in the hypothalamus and liver; ii) muscle, liver, and hypothalamic expression of key genes involved in energy homeostasis control; and iii) hypothalamic miRNA expression patterns. Our study brings new insights concerning the complexity of leptin action in early life to modulate and adapt hypothalamic response to energy homeostasis control later in life and highlights the potential role of miRNAs.

\section{Declaration of interest}

The authors declare that there is no conflict of interest that could be perceived as prejudicing the impartiality of the research reported.

\section{Funding}

From University of Paris-Sud and CNRS.

\section{Author contribution statement}

$C B$ and $D C$ performed the experiments and writing of the manuscript; $\mathrm{HO}$ $\mathrm{H}$ performed the experiments; A G was involved in the production of leptin antagonist and discussion; L A discussed and participated in the experimental design; M T participated in the experimental design, performed experiments, and wrote the manuscript.

\section{References}

Aguirre V, Uchida T, Yenush L, Davis R \& White MF 2000 The c-Jun NH(2)terminal kinase promotes insulin resistance during association with insulin receptor substrate-1 and phosphorylation of Ser(307). Journal of Biological Chemistry 275 9047-9054. (doi:10.1074/jbc.275.12.9047)

Ahima RS \& Flier JS 2000 Leptin. Annual Review of Physiology 62 413-437. (doi:10.1146/annurev.physiol.62.1.413)

Published by Bioscientifica Ltd. http://joe.endocrinology-journals.org DOI: 10.1530/JOE-12-0561
C) 2013 Society for Endocrinology Printed in Great Britain 
Ahima RS, Prabakaran D \& Flier JS 1998 Postnatal leptin surge and regulation of circadian rhythm of leptin by feeding. Implications for energy homeostasis and neuroendocrine function. Journal of Clinical Investigation 101 1020-1027. (doi:10.1172/JCI1176)

Attig L, Solomon G, Ferezou J, Abdennebi-Najar L, Taouis M, Gertler A \& Djiane J 2008 Early postnatal leptin blockage leads to a long-term leptin resistance and susceptibility to diet-induced obesity in rats. International Journal of Obesity 32 1153-1160. (doi:10.1038/ijo.2008.39)

Bautista CJ, Bock L, Larrea F, Nathanielsz PW \& Zambrano E 2009 Effects of a maternal low protein isocaloric diet on milk leptin and progeny serum leptin concentration and appetitive behavior in the first 21 days of neonatal life in the rat. Pediatric Research 63 358-363. (doi:10.1203/ 01.pdr.0000304938.78998.21)

Benomar Y, Roy AF, Aubourg A, Djiane J \& Taouis M 2005a Cross downregulation of leptin and insulin receptor expression and signalling in a human neuronal cell line. Biochemical Journal 388 929-939. (doi:10.1042/BJ20041621)

Benomar Y, Wetzler S, Larue-Achagiotis C, Djiane J, Tomé D \& Taouis M 2005 b In vivo leptin infusion impairs insulin and leptin signalling in liver and hypothalamus. Molecular and Cellular Endocrinology 242 59-66. (doi:10.1016/j.mce.2005.07.003)

Benomar Y, Berthou F, Vacher CM, Bailleux V, Gertler A, Djiane J \& Taouis M 2009 Leptin but not ciliary neurotrophic factor (CNTF) induces phosphotyrosine phosphatase-1B expression in human neuronal cells (SH-SY5Y): putative explanation of CNTF efficacy in leptin-resistant state. Endocrinology 150 1182-1191. (doi:10.1210/en. 2008-1097)

Berthou F, Rouch C, Gertler A, Gerozissis K \& Taouis M 2011 Chronic central leptin infusion differently modulates brain and liver insulin signaling. Molecular and Cellular Endocrinology 337 89-95. (doi:10.1016/ j.mce.2011.02.005)

Beylot M, Pinteur C \& Peroni O 2006 Expression of the adiponectin receptors AdipoR1 and AdipoR2 in lean rats and in obese Zucker rats. Metabolism 55 396-401. (doi:10.1016/j.metabol.2005.09.016)

Bouret SG, Draper SJ \& Simerly RB 2004a Formation of projection pathways from the arcuate nucleus of the hypothalamus to hypothalamic regions implicated in the neural control of feeding behavior in mice. Journal of Neuroscience 24 2797-2805. (doi:10.1523/JNEUROSCI.5369-03.2004)

Bouret SG, Draper SJ \& Simerly RB $2004 b$ Trophic action of leptin on hypothalamic neurons that regulate feeding. Science 304 108-110. (doi:10.1126/science.1095004)

Calegari VC, Torsoni AS, Vanzela EC, Araújo EP, Morari J, Zoppi CC, Sbragia L, Boschero AC \& Velloso LA 2011 Inflammation of the hypothalamus leads to defective pancreatic islet function. Journal of Biological Chemistry 286 12870-12880. (doi:10.1074/jbc.M110.173021)

Carvalheira JB, Siloto RM, Ignacchitti I, Brenelli SL, Carvalho CR, Leite A, Velloso LA, Gontijo JA \& Saad MJ 2001 Insulin modulates leptininduced STAT3 activation in rat hypothalamus. FEBS Letters $\mathbf{5 0 0}$ 119-124. (doi:10.1016/S0014-5793(01)02591-1)

Cho WC 2007 OncomiRs: the discovery and progress of microRNAs in cancers. Molecular Cancer 6 60. (doi:10.1186/1476-4598-6-60)

Elinav E, Niv-Spector L, Katz M, Price TO, Ali M, Yacobovitz M, Solomon G, Reicher S, Lynch JL, Halpern Z et al. 2009 Pegylated leptin antagonist is a potent orexigenic agent: preparation and mechanism of activity. Endocrinology 150 3083-3091. (doi:10.1210/en.2008-1706)

Esau C, Davis S, Murray SF, Yu XX, Pandey SK, Pear M, Watts L, Booten SL, Graham M, McKay R et al. 2006 miR-122 regulation of lipid metabolism revealed by in vivo antisense targeting. Cell Metabolism 3 87-98. (doi:10.1016/j.cmet.2006.01.005)

Férézou-Viala J, Roy AF, Serougne C, Gripois D, Parquet M, Bailleux V, Gertler A, Delplanque B, Djiane J, Riottot M et al. 2007 Long-term consequences of maternal high-fat feeding on hypothalamic leptin sensitivity and diet-induced obesity in the offspring. American Journal of Physiology 293 R1056-R1062.
Fiore R, Siegel G \& Schratt G 2008 MicroRNA function in neuronal development, plasticity and disease. Biochimica et Biophysica Acta 1779 471-478. (doi:10.1016/j.bbagrm.2007.12.006)

Foley NH, Bray I, Watters KM, Das S, Bryan K, Bernas T, Prehn JH \& Stallings RL 2011 MicroRNAs 10a and 10b are potent inducers of neuroblastoma cell differentiation through targeting of nuclear receptor corepressor 2. Cell Death and Differentiation 18 1089-1098. (doi:10.1038/cdd.2010.172)

Hamaya Y, Takeda T, Dohi S, Nakashima S \& Nozawa Y 2000 The effects of pentobarbital, isoflurane, and propofol on immediate-early gene expression in the vital organs of the rat. Anesthesia and Analgesia 90 1177-1183. (doi:10.1097/00000539-200005000-00034)

Herrera BM, Lockstone HE, Taylor JM, Wills QF, Kaisaki PJ, Barrett A, Camps C, Fernandez C, Ragoussis J, Gauguier D et al. 2009 MicroRNA$125 \mathrm{a}$ is over-expressed in insulin target tissues in a spontaneous rat model of type 2 diabetes. BMC Medical Genomics 2 54. (doi:10.1186/ 1755-8794-2-54)

Herrera BM, Lockstone HE, Taylor JM, Ria M, Barrett A, Collins S, Kaisaki P, Argoud K, Fernandez C, Travers ME et al. 2010 Global microRNA expression profiles in insulin target tissues in a spontaneous rat model of type 2 diabetes. Diabetologia 53 1099-1109. (doi:10.1007/s00125010-1667-2)

Huang H, Xie C, Sun X, Ritchie RP, Zhang J \& Chen YE 2010 miR-10a contributes to retinoid acid-induced smooth muscle cell differentiation. Journal of Biological Chemistry 285 9383-9389. (doi:10.1074/jbc. M109.095612)

Inui M, Martello G \& Piccolo S 2010 MicroRNA control of signal transduction. Nature Reviews. Molecular Cell Biology 11 252-263. (doi:10.1038/nrm2868)

Kadowaki T \& Yamauchi T 2005 Adiponectin and adiponectin receptors. Endocrine Reviews 26 439-451. (doi:10.1210/er.2005-0005)

Kirk SL, Samuelsson AM, Argenton M, Dhonye H, Kalamatianos T, Poston L, Taylor PD \& Coen CW 2009 Maternal obesity induced by diet in rats permanently influences central processes regulating food intake in offspring. PLOS ONE 4 e5870. (doi:10.1371/journal.pone. 0005870)

Krek A, Grün D, Poy MN, Wolf R, Rosenberg L, Epstein EJ, MacMenamin P, da Piedade I, Gunsalus KC, Stoffel M et al. 2005 Combinatorial microRNA target predictions. Nature Genetics 37 495-500. (doi:10.1038/ng1536)

Lai EC 2002 Micro RNAs are complementary to 3' UTR sequence motifs that mediate negative post-transcriptional regulation. Nature Genetics 30 363-364. (doi:10.1038/ng865)

Li S, Chen X, Zhang H, Liang X, Xiang Y, Yu C, Zen K, Li Y \& Zhang CY 2009 Differential expression of microRNAs in mouse liver under aberrant energy metabolic status. Journal of Lipid Research 50 1756-1765. (doi:10.1194/jlr.M800509-JLR200)

Livak KJ \& Schmittgen TD 2001 Analysis of relative gene expression data using real-time quantitative PCR and the $2(-$ Delta Delta $C(\mathrm{~T}))$ method. Methods 25 402-408. (doi:10.1006/meth.2001.1262)

Meseguer S, Mudduluru G, Escamilla JM, Allgayer H \& Barettino D 2011 MicroRNAs-10a and -10b contribute to retinoic acid-induced differentiation of neuroblastoma cells and target the alternative splicing regulatory factor SFRS1 (SF2/ASF). Journal of Biological Chemistry $\mathbf{2 8 6}$ 4150-4164. (doi:10.1074/jbc.M110.167817)

Metais C, Forcheron F, Abdallah P, Basset A, Del Carmine P, Bricca G \& Beylot M 2008 Adiponectin receptors: expression in Zucker diabetic rats and effects of fenofibrate and metformin. Metabolism 57 946-953. (doi:10.1016/j.metabol.2008.02.010)

Mistry AM, Swick A \& Romsos DR 1999 Leptin alters metabolic rates before acquisition of its anorectic effect in developing neonatal mice. American Journal of Physiology 277 R742-R747.

Morash B, Wilkinson D, Murphy P, Ur E \& Wilkinson M 2001 Developmental regulation of leptin gene expression in rat brain and pituitary. Molecular and Cellular Endocrinology 185 151-159. (doi:10.1016/S0303-7207(01)00626-8) 
O'Malley D, McDonald N, Mizielinska S, Connolly CN, Irving AJ \& Harvey J 2007 Leptin promotes rapid dynamic changes in hippocampal dendritic morphology. Molecular and Cellular Neurosciences 35 559-572. (doi:10.1016/j.mcn.2007.05.001)

Patel MS, Srinivasan M \& Laychock SG 2009 Metabolic programming: role of nutrition in the immediate postnatal life. Journal of Inherited Metabolic Disease 32 218-228. (doi:10.1007/s10545-008-1033-4)

Plaisance V, Abderrahmani A, Perret-Menoud V, Jacquemin P, Lemaigre F \& Regazzi R 2006 MicroRNA-9 controls the expression of Granuphilin/Slp4 and the secretory response of insulin-producing cells. Journal of Biological Chemistry 281 26932-26942. (doi:10.1074/jbc.M601225200)

Poy MN, Eliasson L, Krutzfeldt J, Kuwajima S, Ma X, Macdonald PE, Pfeffer S, Tuschl T, Rajewsky N, Rorsman P et al. 2004 A pancreatic islet-specific microRNA regulates insulin secretion. Nature 432 226-230. (doi:10. 1038/nature03076)

Proulx K, Richard D \& Walker CD 2002 Leptin regulates appetite-related neuropeptides in the hypothalamus of developing rats without affecting food intake. Endocrinology 143 4683-4692. (doi:10.1210/en. 2002-220593)

Salomon G, Niv-Spector L, Gussakovsky EE \& Gertler A 2006 Large-scale preparation of biologically active mouse and rat leptins and their L39A/D40A/F41A muteins which act as potent antagonists. Protein Expression and Purification 47 128-136. (doi:10.1016/j.pep.2005.09.016)

Samec A, Seydoux J \& Dulloo AG 1999 Post-starvation gene expression of skeletal muscle uncoupling protein 2 and uncoupling protein 3 in response to dietary fat levels and fatty acid composition. A link with insulin resistance. Diabetes 48 436-441. (doi:10.2337/diabetes.48.2. 436)

Schratt GM, Tuebing F, Nigh EA, Kane CG, Sabatini ME, Kiebler M \& Greenberg ME 2006 A brain-specific microRNA regulates dendritic spine development. Nature 439 283-289. (doi:10.1038/nature04367)

Schwartz MW, Woods SC, Porte D Jr, Seeley RJ \& Baskin DG 2000 Central nervous system control of food intake. Nature 404 661-671.

Scott GK, Goga A, Bhaumik D, Berger CE, Sullivan CS \& Benz CC 2007 Coordinate suppression of ERBB2 and ERBB3 by enforced expression of micro-RNA miR-125a or miR-125b. Journal of Biological Chemistry 282 1479-1483. (doi:10.1074/jbc.M609383200)

Smalheiser NR \& Lugli G 2009 microRNA regulation of synaptic plasticity. Neuromolecular Medicine 11 133-140. (doi:10.1007/s12017-009-8065-2)

Stocker C, O'Dowd J, Morton NM, Wargent E, Sennit MV, Hislop D, Glund S, Seckl JR, Arch JRS \& Cawthorn MA 2004 Modulation of susceptibility to weight gain an insulin resistance in low birth weight rats by treatment of their mothers with leptin during pregnancy and lactation. International Journal of Obesity 28 129-136. (doi:10.1038/ sj.ijo.0802476)
Takamura H, Ichisaka S, Watanabe K, Toigawa M \& Hata Y 2008 Effects of anesthesia on immunohistochemical detection of phosphorylated extracellular signal-regulated kinase in cerebral cortex. Journal of Neuroscience Methods 170 300-304. (doi:10.1016/j.jneumeth. 2008.01.005)

Toste FP, de Moura EG, Lisboa PC, Fagundes AT, de Oliveira E \& Passos MC 2006 Neonatal leptin treatment programmes leptin hypothalamic resistance and intermediary metabolic parameters in adult rats. British Journal of Nutrition 95 830-837. (doi:10.1079/BJN20061726)

Tsuchiya H, Ebata Y, Sakabe T, Hama S, Kogure K \& Shiota G 2013 High-fat, high-fructose diet induces hepatic iron overload via a hepcidinindependent mechanism prior to the onset of liver steatosis and insulin resistance in mice. Metabolism: Clinical and Experimental 62 62-69. (doi:10.1016/j.metabol.2012.06.008)

Valerio A 2006 Leptin increases axonal growth cone size in developing mouse cortical neurons by convergent signals inactivating glycogen synthase kinase-3 3. Journal of Biological Chemistry 281 12950-12958. (doi:10.1074/jbc.M508691200)

Vickers MH, Gluckman PD, Coveny AH, Hofman PL, Cutfield WS, Gertler A, Breier BH \& Harris M 2008 The effect of neonatal leptin treatment on postnatal weight gain in male rats is dependent on maternal nutritional status during pregnancy. Endocrinology 149 1906-1913. (doi:10.1210/ en.2007-0981)

Villeneuve LM, Kato M, Reddy MA, Wang M, Lanting L \& Natarajan R 2010 Enhanced levels of microRNA-125b in vascular smooth muscle cells of diabetic $\mathrm{db} / \mathrm{db}$ mice lead to increased inflammatory gene expression by targeting the histone methyltransferase Suv39h1. Diabetes 59 2904-2915. (doi:10.2337/db10-0208)

Vo N, Klein ME, Varlamova O, Keller DM, Yamamoto T, Goodman RH \& Impey S 2005 A cAMP-response element binding protein-induced microRNA regulates neuronal morphogenesis. PNAS 102 16426-16431. (doi:10.1073/pnas.0508448102)

Wang B, Koh P, Winbanks C, Coughlan MT, McClelland A, Watson A, Jandeleit-Dahm K, Burns WC, Thomas MC, Cooper ME et al. 2011 miR-200a prevents renal fibrogenesis through repression of TGF- $\beta 2$ expression. Diabetes 60 280-287. (doi:10.2337/db10-0892)

Yoon MJ, Lee GY, Chung JJ, Ahn YH, Hong SH \& Kim JB 2006 Adiponectin increases fatty acid oxidation in skeletal muscle cells by sequential activation of AMP-Activated protein kinase, p38 mitogen-activated protein kinase, and peroxisome proliferator-activated receptor $\alpha$. Diabetes 55 2562-2570. (doi:10.2337/db05-1322)

Zhao E, Keller MP, Rabaglia ME, Oler AT, Stapleton DS, Schueler KL, Neto EC, Moon JY, Wang P, Wang IM et al. 2009 Obesity and genetics regulate microRNAs in islets, liver, and adipose of diabetic mice. Mammalian Genome 20 476-485. (doi:10.1007/s00335-009-9217-2)

Received in final form 2 April 2013

Accepted 10 April 2013

Accepted Preprint published online 10 April 2013 http://joe.endocrinology-journals.org

DOI: 10.1530/JOE-12-0561
(ㄷ) 2013 Society for Endocrinology Printed in Great Britain
Published by Bioscientifica Ltd. 